\title{
SIKAP DAN PERSEPSI PETANI TERHADAP KAYU ENERGI : KASUS DI KPHP PUNCAKNGENGAS BATULANTEH, SUMBAWA, NTB
}

\author{
(Attitude and Perception of Farmers on Energy Wood: Case at Kphp Puncakngengas \\ Batulanteh, Sumbawa, NTB)
}

\author{
Dian Diniyati \\ Balai Penelitian dan Pengembangan Teknologi Agroforestry, \\ Jalan Raya Ciamis-Banjar Km 4, Po.BOX 5 Ciamis 46201, \\ E-mail: dian_diniyati@yahoo.com
}

Diterima 7 Mei 2019 Direvisi 22 Juli 2019 Disetujui 24 Juli 2019

\begin{abstract}
The purpose of this study was to analyze farmers' responses to knowledge about forests and tree cultivation technology as well as about energy wood. This research was conducted on October 2016 at KPHP Kanarluk Sumbawa RKPH Puncakngengas Batulanteh. The sample consisted of 34 farmers who lived in the forest area and 34 farmers who lived outside the forest area. Data was collected through observation and interviews using questionnaires. The data collected were analyzed by quantitative and qualitative approaches. The measuring instruments used were averages and percentages, presented descriptively. The results of the study showed that farmers' responses to forests were strongly influenced by living conditions. Farmers who lived in the area were very careful in responding while the ones who lived outside the area were more courageous. Likewise, the response to timber species were strongly influenced by their knowledge and experience so that the knowledge of farmers living within the area were very limited. These were related to the attitude shown by farmers that energy wood utilized by farmers were in the form of firewood originating from all species of trees around it. The results of this study were expected to be used as a policy material on the development of energy wood plantation and an increase in farmers' knowledge of energy wood species so that the culture of planting will be increasingly among Sumbawa farmers.
\end{abstract}

Keywords: attitude and perception, energy wood, forest, RKPH Kanarluk Sumbawa

\begin{abstract}
ABSTRAK
Tujuan dari penelitian ini adalah untuk menganalisis tanggapan petani terhadap pengetahuan tentang hutan dan teknologi penanaman pohon, dan juga tentang kayu energi. Penelitian ini dilakukan pada bulan Oktober 2016 di KPHP Kanarluk Sumbawa RKPH Puncakngengas Batulanteh. Sampel terdiri dari 34 petani yang tinggal di dalam kawasan hutan dan 34 petani yang tinggal di luar kawasan hutan. Data dikumpulkan melalui observasi dan wawancara menggunakan kuisioner. Sedangkan data terkumpul dianalisis dengan pendekatan kuantitatif dan kualitatif. Alat ukur yang digunakan adalah rata-rata dan persentase, disajikan secara deskriptif. Hasil penelitian menunjukkan bahwa respon petani terhadap hutan sangat dipengaruhi oleh kondisi tempat tinggal. Petani yang tinggal di dalam kawasan sangat berhati-hati dalam memberikan respon sedangkan petani yang tinggal di luar kawasan lebih berani. Demikian juga respon tentang jenis-jenis tanaman kayu sangat dipengaruhi oleh pengetahuan dan pengalamannya sehingga pengetahuan petani yang tinggal di dalam kawasan sangat terbatas. Hal ini berkaitan dengan sikap yang ditunjukkan oleh petani bahwa kayu energi yang dimanfaatkan oleh petani berupa kayu bakar yang berasal dari seluruh jenis kayu yang ada disekitarnya. Hasil penelitian ini diharapkan dapat dijadikan sebagai bahan kebijakan tentang pengembangan tanaman kayu energi serta peningkatan pengetahuan petani tentang tanaman kayu sehingga budaya menanam akan semakin meningkat di kalangan petani Sumbawa.
\end{abstract}

Kata kunci: hutan, kayu energi, RKPH Kanarluk Sumbawa, sikap dan persepsi 


\section{PENDAHULUAN}

Salah satu fungsi hutan adalah sebagai sumber pendapatan bagi masyarakat terutama masyarakat yang berada disekitar kawasan hutan. Bagi masyarakat yang berada dan tinggal di sekitar hutan, keberadaan hutan ini sangat berarti sekali bagi kesejahteraannya. Dimana hutan mampun menjalankan fungsi ekonomi, sosial dan ekologi dengan baik (Suryaningsih, Punaweni, \& Izzati, 2012).

Kondisi ini memicu terjadinya interaksi yang tinggi antara masyarakat dengan hutan, sehingga tercipta banyak aktivitas di kawasan hutan yang dapat mempengaruhi ekosistem hutan. Dimana pola pemanfaatan lahan dan sumberdaya hutan yang ideal harus mampu didukung oleh kesadaran untuk menjaga serta mengoptimalkan setiap elemen yang terlibat di dalamnya (Masria, Golar, \& Ihsan, 2015). Oleh karena itu interaksi tersebut dapat menumbuhkan perilaku masyarakat dalam pemeliharaan hutan, hal ini berkaitan dengan persepsi masyarakat mengenai hutan. Sikap masyarakat dalam memperlakukan hutan dipengaruhi oleh pengalaman dan pengetahuan mengenai kondisi hutan itu sendiri dan ini semua dipengaruhi oleh tingkat pendidikan masyarakat (Winanti, 2010) (Indiyah, Ninuk, Pang, \& Hardjanto, 2017).

Kondisi ini telah terjadi pada masyarakat yang berada di sekitar kawasan hutan KPHP Puncakngengas Batulanteh RKPH Kanarluk Sumbawa, dimana masyarakatnya telah memiliki persepsi dan sikap terhadap pengelolaan kawasan hutan. Selanjutnya, pada kondisi tersebut dilakukan penelitian dengan melakukan intervensi berupa kegiatan penelitian tentang pengembangan tanaman kayu energi yaitu kaliandra dan akor di kawasan hutan tersebut. Adanya kegiatan penelitian ini akan menimbulkan reaksi berupa respon terhadap kegiatan penelitian kayu energi ini.

Berdasarkan kondisi tersebut, maka cukup menarik untuk dilakukan kajian tentang persepsi dan sikap masyarakat. Respon yang ditunjukkan oleh masyarakat ini merupakan kondisi nyata di lapangan. Oleh karena itu maka penelitian ini bertujuan untuk menganalisis respon petani terhadap pengetahuan tentang hutan dan teknologi budidaya tanaman kayu serta respon petani terhadap pengetahuan kayu energy. Diharapkan hasil penelitian ini dapat memberikan informasi tentang kondisi nyata di lapangan tentang respon petani terhadap hutan dan kayu energi. Selanjutnya informasi ini diharapkan dapat dijadikan sebagai bahan evaluasi dan kebijakan pengembangan bidang kehutanan kususnya pengembangan kayu energi.

\section{METODE PENELITIAN}

Model pendekatan penelitian ini adalah kuantitatif dan kualitatif. Dalam model ini penelitian menggunakan beberapa metode yang berbeda pada saat pengambilan data dilapangan (Sarwono, 2006.). Penelitian dengan pendekatan kuantiatif dan kualitatif ini bermaksud menggambarkan dan menguraikan mengenai respon dari responden mengenai kayu energy yang akan dikembangkan di wilayah KPHP Puncakngengas Bantulanteh Sumbawa. Penelitian ini dilaksanakan pada bulan Oktober 2016. Lokasi penelitian merupakan demplot peningkatan produktivitas lahan agroforestri berbasis kayu energy, yang terletak di Desa Labuhan Badas Dusun Kayu madu. Responden adalah petani yang tinggal di dalam kawasan hutan KPHP Puncakngengas Batulanteh RKPH Kanarluk sebanyak 34 orang, sebagai pembanding juga dilakukan penelitian kepada responden sebanyak 34 orang yang tinggal diluar kawasan hutan yang tidak menggarap di lahan Negara akan tetapi jarak rumah berdekatan dengan lokasi penelitian.

Data yang diperlukan adalah data primer yang dikumpulkan secara langsung dengan metode observasi dan wawancara menggunakan quisioner serta wawancara terbuka/berkembang untuk lebih menggali 
lagi tentang respon responden terhadap pengembangan kayu energy. Data sekunder diperlukan untuk lebih mendukung informasi dan data yang sudah diperoleh dari responden. Data sekunder ini dikumpulkan dari penelusuran pustaka dan laporan dari instansi yang terkait dengan penelitian.

Data yang terkumpul di ukur dengan menggunakan alat ukur rata-rata dan persentase, selanjutnya disajikan secara deskriptif supaya dapat menjelaskan secara menyeluruh tentang respon responden perihal pengembangan kayu energy berdasarkan nilai persentase jumlah responden. Data yang dianalisis yaitu respon masyarakat yang terlibat dalam kegiatan penelitian dibandingkan dengan respon masyarakat yang tidak terlibat dalam kegiatan penelitian.

\section{HASIL DAN PEMBAHASAN}

\section{A. Respon Petani Terhadap Pengetahuan tentang Hutan dan Teknologi Budidaya Tanaman Kayu}

Penduduk yang tinggal di dalam dan sekitar kawasan hutan KPHP Puncakngengas Batulanteh RPH Kanar Luk pada umumnya merupakan masyarakat pendatang yang berasal dari Lombok, Bima, Bali, Medan, Sumbawa dan Sasak (Diniyati \& Siarudin, n.d.). Walaupun bukan penduduk lokal namun interaksi dengan lingkungannya sudah terjalin

Tabel 1. Persepsi Petani tentang Hutan

Table 1. Farmers' perception about forest sedemikian rupa karena sumber kehidupan masyarakat seluruhnya berasal dari alam sekitar (hutan), masyarakat merasakan manfaat yang besar dengan adanya hutan yaitu bisa bercocok tanam, sumber kayu bakar, sumber air dan lain-lain. Adapun persepsi masyarakat lebih rinci seperti uraian berikut ini:

\section{Persepsi Petani tentang Hutan}

Petani yang tinggal didalam kawasan dan diluar kawasan melalui panca inderanya telah memiliki tanggapan terhadap keberadaan sumberdaya hutan setelah mengamati dan merasakan manfaatnya. Menurut (Triyanto, 2009) persepsi memiliki sifat yang sangat subyektif, yaitu tergantung pada subyek yang melakukan persepsi tersebut dan juga dipengaruhi oleh keadaan tertentu yang akan memberikan reaksi/perilaku yang berbeda pula. Respon petani tentang kondisi hutan sangat beragam sekali, seperti tersaji pada Tabel 1. Keputusan (respon) petani terhadap kondisi hutan atau upaya memulihkan kondisi hutan sangat dipengaruhi oleh persepsi petani terhadap dampak ekonomi dan lingkungan dari pemulihan lingkungan tersebut, dan juga kebijakan yang mempromosikan pemulihan tersebut (Trevisan, Schmitt-filho, Farley, Fantini, \& Longo, 2016).

\begin{tabular}{|c|c|c|c|c|c|}
\hline No & $\begin{array}{c}\text { Persepsi Petani } \\
\text { Farmers' perception }\end{array}$ & $\begin{array}{l}\text { Petani di dalam } \\
\text { kawasan hutan } \\
\text { (orang) } \\
\text { Farmers in the } \\
\text { forest area } \\
\text { (people) }\end{array}$ & $\begin{array}{l}\text { Persentase } \\
(\%) \\
\text { Percentage } \\
(\%)\end{array}$ & $\begin{array}{l}\text { Petani di luar } \\
\text { kawasan hutan } \\
\text { (orang) } \\
\text { Farmers } \\
\text { outside the } \\
\text { forest area } \\
\text { (people) }\end{array}$ & $\begin{array}{l}\text { Persentase } \\
(\%) \\
\text { Percentage } \\
(\%)\end{array}$ \\
\hline 1 & $\begin{array}{l}\text { Pengertian hutan menurut petani } \\
\text { Understanding of forests according to } \\
\text { farmers }\end{array}$ & & & & \\
\hline & $\begin{array}{l}\text { - Tidak memberikan jawaban } \\
\text { Do not give answers }\end{array}$ & 18 & 52.94 & 11 & 32.35 \\
\hline & $\begin{array}{l}\text { - Tempat mencari nafkah } \\
\text { Place to earn income }\end{array}$ & 4 & 11.76 & 0 & 0.00 \\
\hline
\end{tabular}




\begin{tabular}{|c|c|c|c|c|c|}
\hline No & $\begin{array}{c}\text { Persepsi Petani } \\
\text { Farmers' perception }\end{array}$ & $\begin{array}{l}\text { Petani di dalam } \\
\text { kawasan hutan } \\
\text { (orang) } \\
\text { Farmers in the } \\
\text { forest area } \\
\text { (people) }\end{array}$ & $\begin{array}{l}\text { Persentase } \\
\quad(\%) \\
\text { Percentage } \\
\quad(\%)\end{array}$ & $\begin{array}{c}\text { Petani di luar } \\
\text { kawasan hutan } \\
\text { (orang) } \\
\text { Farmers } \\
\text { outside the } \\
\text { forest area } \\
\text { (people) } \\
\end{array}$ & $\begin{array}{l}\text { Persentase } \\
(\%) \\
\text { Percentage } \\
(\%)\end{array}$ \\
\hline & $\begin{array}{l}\text { - Tempatnya di gunung } \\
\text { The place is on the mountain }\end{array}$ & 1 & 2,94 & 0 & 0,00 \\
\hline & $\begin{array}{l}\text { - Paru-paru dunia yang harus di jaga, } \\
\text { selain itu terdapat sumber mata air, } \\
\text { tempat tinggal binatang serta } \\
\text { penghasil madu } \\
\text { The lungs of the world that must be } \\
\text { maintained, besides that there are } \\
\text { sources of springs, animal habitats } \\
\text { and honey producers }\end{array}$ & 3 & 8.82 & 15 & 44.12 \\
\hline & $\begin{array}{l}\text { - Lahan milik negara untuk ditanami } \\
\text { pepohonan } \\
\text { State land to plant trees }\end{array}$ & 8 & 23.53 & 5 & 14.71 \\
\hline & $\begin{array}{l}\text { - Lahan yang masih liar yang belum } \\
\text { dirabas (dicangkul dan dibersihkan) } \\
\text { Wild land that has not been razed } \\
\text { (hoeed and cleaned) }\end{array}$ & 0 & 0.00 & 3 & 8.82 \\
\hline & sub total sub-total & 34 & 100 & 34 & 100 \\
\hline \multirow[t]{11}{*}{2} & $\begin{array}{l}\text { Pengertiantentang hasil hutan } \\
\text { Understanding of forest products }\end{array}$ & & & & \\
\hline & a. Kayu Wood & & & & \\
\hline & $\begin{array}{l}\text { - Tidak memberikan jawaban } \\
\text { Do not give answers }\end{array}$ & 29 & 85.29 & 13 & 38.24 \\
\hline & $\begin{array}{l}\text { - Berbagai jenis kayu (jati, mahoni dan } \\
\text { gmelina), bambu serta kayu bakar } \\
\text { Various species of wood (teak, } \\
\text { mahogany and gmelina), bamboo } \\
\text { and firewood }\end{array}$ & 5 & 14.71 & 21 & 61.76 \\
\hline & sub total Sub-total & 34 & 100 & 34 & 100 \\
\hline & b. Non Kayu Non-wood & & & & \\
\hline & $\begin{array}{l}\text { - Tidak memberikan jawaban } \\
\text { Do not give answers }\end{array}$ & 29 & 85.29 & 18 & 52.94 \\
\hline & $\begin{array}{l}\text { - Madu, air, batu, pasir dan binatang } \\
\text { Honey, water, stone, sand and animals }\end{array}$ & 4 & 11.76 & 5 & 14.71 \\
\hline & $\begin{array}{l}\text { - Pertanian (asam, mente, jagung, padi, } \\
\text { kelapa, lebui) } \\
\text { Agriculture (tamarind, cashew, corn, } \\
\text { rice, coconut, lebui) }\end{array}$ & 1 & 2.94 & 10 & 29.41 \\
\hline & $\begin{array}{l}\text { - Rumput pakan ternak } \\
\text { Animal feed grass }\end{array}$ & 0 & 0.00 & 1 & 2.94 \\
\hline & sub total Sub-total & 34 & 100 & 34 & 100 \\
\hline \multirow[t]{2}{*}{3} & $\begin{array}{l}\text { Pengertian tentang pertanian menetap } \\
\text { Definition of settled agriculture }\end{array}$ & & & & \\
\hline & $\begin{array}{l}\text { - Tidak memberikan jawaban } \\
\text { Do not give answers }\end{array}$ & 19 & 55.88 & 16 & 47.06 \\
\hline
\end{tabular}




\begin{tabular}{|c|c|c|c|c|c|}
\hline No & $\begin{array}{c}\text { Persepsi Petani } \\
\text { Farmers'perception }\end{array}$ & $\begin{array}{l}\text { Petani di dalam } \\
\text { kawasan hutan } \\
\text { (orang) } \\
\text { Farmers in the } \\
\text { forest area } \\
\text { (people) }\end{array}$ & $\begin{array}{l}\text { Persentase } \\
\quad(\%) \\
\text { Percentage } \\
(\%)\end{array}$ & $\begin{array}{l}\text { Petani di luar } \\
\text { kawasan hutan } \\
\text { (orang) } \\
\text { Farmers } \\
\text { outside the } \\
\text { forest area } \\
\text { (people) } \\
\end{array}$ & $\begin{array}{l}\text { Persentase } \\
(\%) \\
\text { Percentage } \\
(\%)\end{array}$ \\
\hline & $\begin{array}{l}\text { - Pertanian yang dilakukan secara terus } \\
\text { menerus dan tidak pindah-pindah, } \\
\text { terutama bisa ditanami padi, jagung } \\
\text { dan kacang } \\
\text { Agriculture that is carried out } \\
\text { continuously and does not move } \\
\text { around, can mainly be planted with } \\
\text { rice, corn and beans }\end{array}$ & 15 & 44.12 & 12 & 35.29 \\
\hline & $\begin{array}{l}\text { - tanaman yang tetap tiap tahun } \\
\text { diambil hasilnya, seperti kelapa dan } \\
\text { mente } \\
\text { Plants that are harvested annually, } \\
\text { such as coconut and cashew }\end{array}$ & 0 & 0.00 & 6 & 17.65 \\
\hline & sub total Sub-total & 34 & 100.00 & 34 & 100.00 \\
\hline
\end{tabular}

Sumber (Sources): diolah dari data primer (analyzed from primary data), 2016

Petani yang berada di dalam kawasan hutan sangat tergantung sekali terhadap keberadaan hutan KPH Puncakngengas Batulanteh RPH Kanar Luk sehingga dalam merespon pertanyaan tentang kondisi hutan, hasil hutan dan pertanian menetap sangat berhati-hati sekali dalam memberikan jawaban, petani lebih banyak tidak memberikan jawaban atas pertanyaan tersebut, yaitu sebesar 52,94\% (pengertian hutan), 85,29\% (hasil hutan kayu), 85,29\% (hasil hutan non kayu) dan 55,88\% (pertanian menetap). Lain halnya dengan petani yang berada di luar kawasan hutan memberikan respon tentang kondisi hutan, hasil hutan kayu dan non kayu serta pertanian menetap, hanya sedikit sekali yang tidak memberi jawaban yaitu 32,35\% (pengertian hutan), 38,24\% (hasil hutan kayu), 52,94\% (hasil hutan non kayu) dan 47,06\% (pertanian menetap). Respon petani di luar kawasan hutan lebih bervariasi, karena adanya perasaan aman dan tidak ada rasa ketakutan dalam memberikan pendapat, dikarenakan ketergantungan petani terhadap kawasan hutan tidaklah banyak. Keragu-raguan petani dalam menyampaikan persepsinya tentang hutan kemungkinan takut muncul kecurigaan terhadap ekploitasi hutan yang berlebihan, karena persepsi petani terhadap hutan biasanya dihubungkan dengan isu ekonomi dan lingkungan (Dolisca, Mcdaniel, \& Teeter, 2007).

Menurut petani hutan adalah lahan milik Negara untuk ditanami pohon dan merupakan paru-paru dunia yang harus dijaga, tempat sumber air, tempat tinggal binatang, tempat mencari nafkah dan letaknya di gunung. Namun petani di luar kawasan hutan memberikan respon yang lebih berani yaitu hutan merupakan lahan yang masih liar yang belum dirabas (dicangkul dan dibersihkan). Pendapat yang disampaikan oleh petani ini didasarkan atas kondisi harian yang dilakukan dan dilihat dalam memanfaatkan sumberdaya hutan tersebut. Persepsi ini semua menurut (Mamuko, Walangitan, \& Tilaar, 2016) termasuk pada persepsi tinggi yaitu petani memiliki pemahaman yang baik terhadap hutan dan fungsinya, mengaplikasikannya dalam sistem usahatani serta bersedia berpartisipasi dalam menjaga dan melestarikan sumberdaya alam untuk mempertahankan produktivitas lahan serta bertanggungjawa terhadap dampak erosi yang akan ditimbulkan. 
Respon seluruh petani tentang hasil hutan berupa kayu dan non kayu hampir sama, dimana respon yang disampaikan oleh seluruh petani ini didasarkan dari pengalaman setiap hari yang dilakukan/dikerjakan oleh petani serta apa yang dilihatnya setiap hari mengenai semua jenis tanaman yang ada di hutan. Respon seluruh petani mengenai pertanian menetap adalah lahan yang setiap saat dapat ditanami oleh tanaman palawija terutama padi, dan juga tanaman tahunan yang dapat diambil hasilnya setiap tahun seperti kelapa dan mente.

\section{Persepsi Petani tentang Tanaman Kayu}

Pengetahuan petani di seluruh lokasi penelitian tentang tanaman kayu sangat terbatas sekali, hal ini berdasarkan atas pengetahuan yang dilihatnya setiap hari yang ada di sekitarnya, sangat sedikit sekali informasi dari luar yang diterima oleh petani. Oleh karena itu pengetahuan variasi jenis kayu yang diketahui oleh petani terutama petani di dalam kawasan sangat sedikit sekali. Variasi jenis tanaman kayu yang diketahui hanyalah jenis-jenis yang tumbuh dan hidup di alam sekitarnya. Ada beberapa jenis tanaman kayu yang sangat diketahui oleh petani di seluruh lokasi penelitian yaitu tanaman jati dan mahoni. Namun bagi petani yang berada di luar kawasan hutan jenis tanaman kayu yang diketahui lebih banyak variasinya, petani bisa menyebutkan jenis lainnya seperti : gmelina, lamtoro, gamal dan johar.

Petani tidak mengetahui kelompok penggunaan tanaman kayu tersebut, kayu yang ada di di kawasan dan kebun tersebut dimanfaatkan sebagai bahan untuk membangun rumah, peralatan rumah tangga dan sebagai energy rumah tangga, sehingga jika ditanyakan secara spesifik jenis tanaman kayu energy, maka seluruh petani $(100 \%)$ di kedua lokasi penelitian tidak mengetahui jenis kayu energy. Biasanya petani memanfaatkan sembarang kayu untuk keperluan memasak. Seluruh petani menggunakan kayu bakar dengan memanfaatkan ranting dan batang serta batok kelapa, dan pelapah kelapa yang sudah kering dan sudah jatuh ke tanah, terutama bagi petani yang berada di dalam kawasan hutan sangat berhati-hati sekali dalam mengambil kayu bakar di hutan, karena petani mengetahui hukuman bagi yang menebang kayu di kawasan adalah penjara. (Diniyati, tata niaga kayu energy, IJRF)

Dengan keterbatasan pengetahuan petani di seluruh lokasi penelitian mengenai tanaman kayu, maka respon petani yang tinggal di dalam kawasan hutan, tentang jenis-jenis kayu yang kusus untuk kayu energy adalah seluruh kayu yang ada di kawasan hutan, karena setiap hari petani hanya melihat kayu-kayu tersebut dan kayukayu dimanfaatkan sebagai bahan energy rumah tangga. Sedangkan bagi petani yang berada di luar kawasan hutan seluruhnya $(100 \%)$ tidak mengetahui tentang jenis-jenis tanaman kayu yang termasuk kayu energy yang ada di dalam kawasan hutan. Respon ini tercipta dikarenakan petani di luar kawasan seluruhnya (100\%) sangat jarang sekali pergi ke dalam kawasan hutan.

\section{Persepsi Petani tentang Teknologi Pengembangan Tanaman Kayu}

Pengetahun petani tentang jenis-jenis tanaman kayu ini sangat terbatas, karena petani hanya bisa menyebutkan jenis-jenis kayu yang banyak terdapat di dalam kawasan saja dan ini berdampak pula terhadap terbatasnya pengetahuan petani tentang teknologi pengembangan tanaman kayu. Ada 23 orang $(67,65 \%)$ petani di dalam kawasan hutan yang pernah ikut terlibat dalam kegiatan pembibitan tanaman kayu jati dan mahoni, keterlibatnya juga karena adanya kegiatan proyek di KPHP Puncakngengas Batulanteh, dengan demikian kegiatan pembibitan ini bukan karena keinginan sendiri. Selanjutnya bibit kayu tersebut akan di tanam di kawasan hutan. Sedangkan petani di luar kawasan hutan hanya 11 orang $(32,35 \%)$ yang pernah membibitkan tanaman kehutanan. Namun pembibitan tersebut dilakukan bukan karena adanya proyek 
melainkan karena keinginan sendiri untuk membuat bibit tanaman kayu, selanjutnya tanaman kayu tersebut akan di tanam di lahan milik. Alasannya adalah tanaman kayu dapat dipergunakan nantinya untuk membangun rumah.

Terbatasnya petani dalam kegiatan pembibitan dan penanam kayu ini juga berdampak terhadap pengetahuan teknologi pengembangan kayu energy. Seluruh petani (100\%) belum pernah melakukan pembibitan jenis tanaman kayu energy jenis kaliandra dan akor, oleh karena itu seluruh petani belum pernah menanam serta tidak mengetahui bentuk dan jenisnya. Hanya ada satu orang (3\%) petani di dalam kawasan hutan dan dua orang $(6 \%)$ petani di luar kawasan hutan yang pernah mengetahui jenis kaliandra, karena pernah melihat teknik budidaya tanaman kaliandra dan akor di daerah asalnya yaitu Lombok dan Bali.

Petani di lokasi penelitian tidak mengetahui teknologi budidaya kaliandra dan akor sehingga tidak mengerti jika jenis kaliandra dan akor ini pun dapat dikembangkan di kawasan hutan RPH Kanar Luk. Ketidak tahuan petani tentang budidaya tanaman kayu khususnya kaliandra dan akor ini disebabkan karena beberapa hal, diantaranya yaitu kurangnya informasi tentang teknik budidaya tanaman kayu yang dapat diakses oleh para petani selain itu juga karena ada kehawatiran petani jika tanaman akor dan kaliandra dikembangkan di lahan hutan RPH Kanarluk dapat mengurangi luas lahan para petani penggarap tersebut. Kurang minatnya petani mengadopsi teknologi baru biasanya disebabkan tidak ada kepastian tentang outcome dari teknologi tersebut (Hong-qing, Fei, \& Yao-yang, 2017) . Trust sesama petani bisa sangat membantu proses adopsi teknologi baru tersebut, karena petani lebih mengandalkan informasi yang berasal dari sesama petani dibandingkan dari sumber utama seperti internet

\section{Persepsi Petani tentang Pemasaran Kayu}

Kegiatan pengembangan kayu di wilayah yang berdekatan dengan kawasan sangatlah sensitive, akibatnya petani di luar kawasan hutan belum mengembangkan tanaman kayu dengan maksimal. Salah satu alasannya yaitu karena ketakutan petani jika menebang kayu walaupun dari lahan sendiri dianggap telah mencuri kayu dari kawasan, karena jenis yang dikembangkan oleh petani juga hampir sama dengan yang dikembangkan di kawasan. Demikian halnya dengan petani yang tinggal di dalam kawasan hutan, para petani menyadari dan mengatahui bahwa kayu yang ada di kawasan tersebut merupakan milik Negara yang harus dijaga jangan sampai mati bahkan dicuri oleh pihak lain. Keterlibatan petani dalam melakukan kegiatan pencegahan dan pemberantasan perusakan hutan memiliki peran yang sangat signifikan dalam rangka menjaga kelestarian hutan (Syaprillah, 2015).

Situasi ini menyebabkan seluruh petani belum pernah melakukan kegiatan penjualan kayu, demikian juga informasi tentang penjualan kayu energy tidak ketahui oleh seluruh responden. Bahkan untuk kayu bakar juga tidak pernah ada yang bertansaksi jual beli.

\section{B. Analisis Respon Petani terhadap Pengetahuan Kayu Energi}

\section{Sikap Petani Tentang Kayu Energi}

Sikap adalah tindakan seseorang yang dilakukan terhadap sesuatu berdasarkan persepsi dan motivasinya (Triyanto, 2009). Sikap merupakan semacam kesiapan untuk beraksi terhadap suatu objek dengan cara-cara tertentu dan diimplikasikan dalam bentuk perilaku atau tindakan terhadap pemanfaatan sumberdaya hutan berupa kayu energi.

\section{a. Sikap Petani tentang Kayu Energi yang Dimanfaatkan Dalam Bentuk Kayu Bakar}

Sikap petani di ke dua lokasi pada umumnya adalah setuju 73,53\% (Petani di dalam kawasan) dan $88,24 \%$ (petani di luar 
kawasan), tidak setuju $5,88 \%$ (di dalam kawasan) dan $11,76 \%$ (di luar kawasan hutan), tidak berpendapat 20,59\% (petani di dalam kawasan) seperti ditampilkan pada Gambar 1.

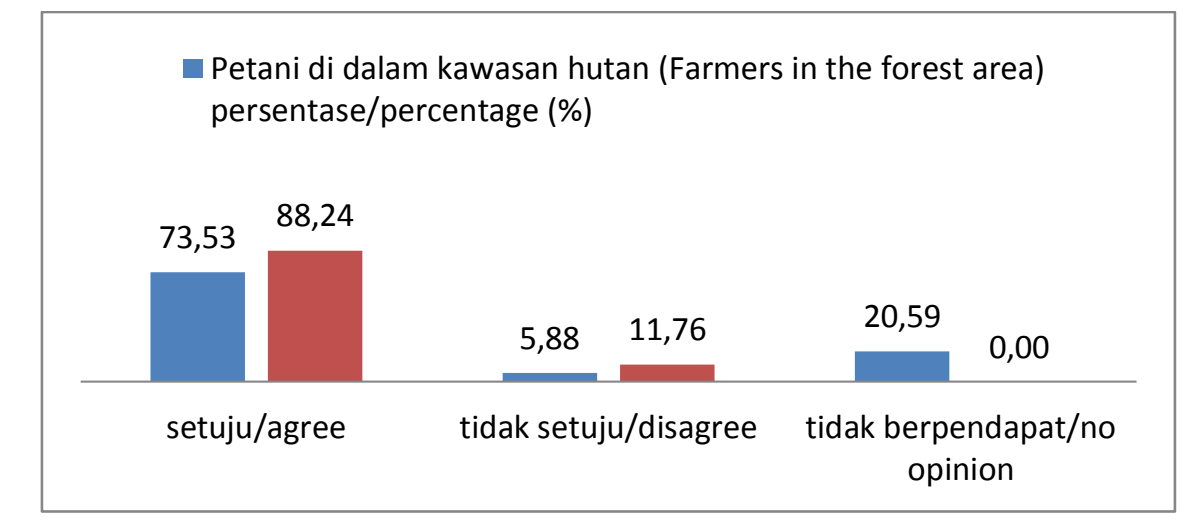

Sumber (Source): Sumber; diolah dari data primer (analyzed from primary data), 2016.

Gambar 1. Sikap petani tentang Kayu Energi yang dimanfaatkan dalam bentuk kayu bakar.

Figure 1. The farmer's attitude about Wood Energy which is utilized in the form of Firewood

Sikap setuju petani terhadap pernyataan bahwa kayu energy dimanfaatkan oleh petani sebegai kayu bakar karena petani di kedua lokasi untuk kegiatan aktivitas rumah tangga seperti memasak menggunakan kayu bakar. Kayu bakar yang dihasilkan oleh petani hanya untuk memenuhi konsumsi sendiri dan tidak pernah diperjual belikan. Seperti juga masyarakat di sekitar Taman Nasional Lore Lindu, memanfaatkan kayu bakar yang diambil dari taman nasional Lore Lindu untuk dikonsumsi sendiri seperti kegiatan memasak dan kegiatan pesta (Neil, Golar, \& Hamzari, 2016). Kayu bakar yang digunakan oleh petani di peroleh dari ladang dekat rumah ataupun di dalam kawasan hutan.

Sementara itu, sikap tidak setuju yang disampaikan oleh petani disebabkan karena bahan bakar yang digunakan untuk kegiatan rumah tangga tidak menggunakan kayu bakar melainkan minyak tanah dan gas. Paling banyak petani menyatakan sikap tidak setuju yaitu berasal dari petani yang tinggal di luar kawasan hutan, sikap ini dimungkinkan karena akses untuk mendapatkan minyak tanah dan gas lebih mudah dibandingkan dengan petani yang tinggal di dalam kawasan. Adapun sikap tidak berpendapat yang ditunjukkan oleh petani di dalam kawasan hutan disebabkan karena rasa ketakutan jika mengambil kayu dari kawasan walupun yang sudah jatuh dapat digolongkan sebagai pelanggaran.

\section{b. Sikap petani tentang bentuk pengolahan kayu energy}

Bentuk pengolahan kayu energy sangat banyak dipasaran diantaranya yaitu sebagai briket arang, wood pelet, kayu bakar, cuka kayu. Akan tetapi sampai penelitian ini dilakukan, bentuk kayu energy yang utama digunakan di wilayah Sumbawa adalah kayu bakar, baik itu oleh rumah tangga maupun industry rumah tangga (Diniyati, n.d.). Oleh karena itu respon yang disampaikan oleh petani terhadap pernyataan tersebut adalah setuju 61,76\% (petani di dalam kawasan) dan 47,06\% (petani diluar kawasan hutan); tidak setuju 14,71\% (petani di dalam kawasan) dan 2,94\% (petani di luar kawasan hutan); tidak berpendapat 23,53\% (petani di dalam kawasan hutan) dan 50\% (petani di luar kawasan hutan) seperti ditampilkan pada Gambar 2.

Alasan yang disampaikan oleh petani kenapa bersikap setuju karena petani merasa bahwa kayu energy itu hanya kayu bakar saja, sedangkan yang bersikap tidak setuju 
mengharapkan pemerintah memberikan melakukan penyuluhan tentang kayu energy ini, demikian juga yang sikap tidak berpendapat karena belum pernah mendengar tentang kayu energy.

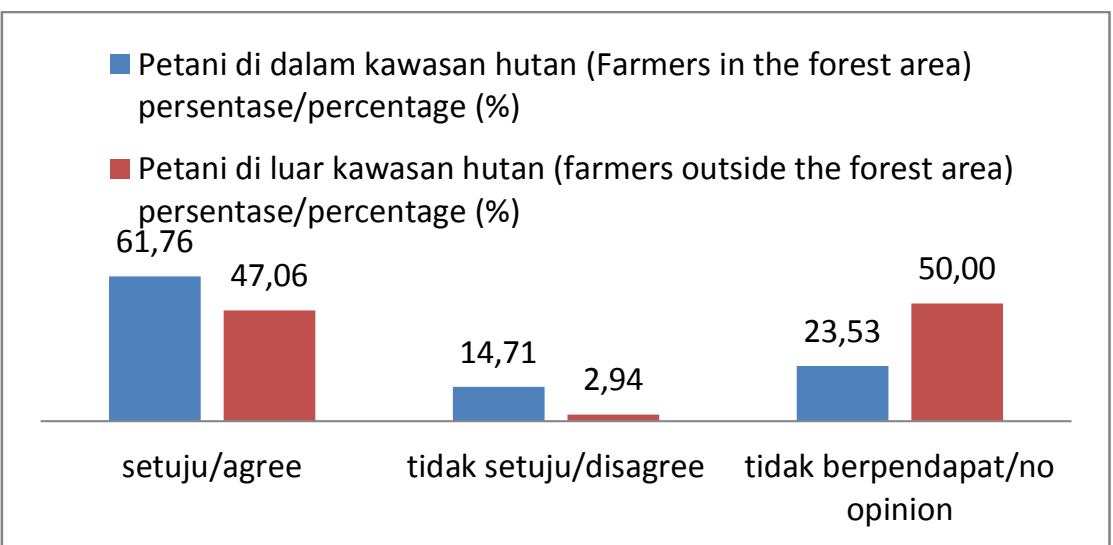

Sumber (Source): Sumber; diolah dari data primer (analyzed from primary data), 2016.

Gambar 2. Sikap petani tentang bentuk pengolahan kayu energy

Figure 2. The attitude of farmers about the form of energy wood processing

Berbeda halnya dengan pemanfaatan kayu energy di negara maju seperti Jepang, petani sudah familiar terhadap variasi pemanfaatan kayu energy dan lebih menyukai pemanfaatannya dalam bentuk wood pellet karena proses pengolahannya bisa menciptakan kesempatan kerja (Nishiguchi \& Tabata, 2016). Oleh karena itu, penyuluhan tentang bentuk-bentuk pemanfaatan kayu energy dan manfaat ekonomi dan lingkungan yang ditimbulkan penting diberikan pada petani di lokasi penelitian.

\section{KESIMPULAN DAN SARAN}

Pengetahuan petani tentang hutan sangat dipengaruhi oleh aktivitas pertanian yang dilakukan sehingga respon yang diberikan petani tentang kondisi hutan dan tanamannya didasarkan pada apa yang setiap hari dilakukan dan dilihatnya, sehingga tidaklah mengherankan jika pengetahuannya hanya terbatas pada jenis tanaman hutan yang sering dijumpainya. Ditambah lagi informasi tentang hutan dan kehutanan bagi petani di sekitar kawasan sangat terbatas baik itu yang disampaikan maupun yang dapat diakses oleh petani, selain itu adanya respon negative dari petani yang berbatasan dengan kawasan hutan tentang pengembangan tanaman kayu di lahan milik menyebabkan jenis tanaman kehutanan yang dibudidayakan sangat sedikit jumlahnya kalah dengan tanaman perkebunan (jambu mente). Pengetahuan petani tentang jenis kayu energy adalah seluruh kayu yang terdapat disekitar lingkunganya sehingga tidak mengetahui jenis kayu kaliandra dan akor merupakan salah satu kayu energy. Respon petani tentang pemanfaatakan kayu energy hanya sebatas sebagai kayu bakar.

Dengan kondisi yang dimikian maka pengetahuan petani tentang tanaman kayu pelu ditingkatkan dengan cara dilakukan penyuluhan tentang jenis-jenis tanaman kayu dan serta sosialisasi tentang peraturan pengembangan tanaman kayu di lahan milik. Kegiatan ini dapat dilakukan dalam rangka pemberdayaan masyarakat yang berada di sekitar kawasan hutan oleh instansi terkait atapun lembaga penelitian dan pendidikan lainnya. Diharapkan adanya perbedayaan tersebut dapat menambah pengetahuan petani sehingga dapat meningkatkan budaya menanam tanaman kayu. 


\section{UCAPAN TERIMA KASIH}

Penulis mengucapkan terima kasih kepada Balai Penelitian Teknologi Agroforestry yang mendanai kegiatan penelitian ini, Kepala dan Staf KPHP Batulanteh Kabupaten Sumbawa yang telah mendampingi selama kegiatan penelitian dilakukan, masyarakat yang berada di sekitar kawasan hutan RKPH Kanar Luk yang telah bersedia mengikuti seluruh tahapan kegiatan penelitian serta teknisi yang telah membantu pengumpulan data dilapangan.

\section{DAFTAR PUSTAKA}

Diniyati, D. (n.d.). Firewood Development in Sumbawa Regency: Consumtion, Tranding System and Determinats. Indonesian Journal of Forestry Research.

Diniyati, D., \& Siarudin, M. (n.d.). Kajian Sejarah Penggarapan Kawasan Hutan di Wilayah Kesatuan Pengelolaan Hutan Produksi Batulanteh, Kabupaten Sumbawa. Jurnal Penelitian Sosial Dan Ekonomi Kehutanan.

Dolisca, F., Mcdaniel, J. M., \& Teeter, L. D. (2007). Farmers $\hat{a} €^{\mathrm{TM}}$ perceptions towards forests : A case study from Haiti. Forest Policy and Economics, 9, 704-712. http://doi.org/10.1016/j.forpol.2006.07.001

Hong-qing, L. I., Fei, Z., \& Yao-yang, Z. (2017). Farmer behavior and perceptions to alternative scenarios in a highly intensive agricultural region, south central China. Journal of Integrative Agriculture, 16(8), 1852-1864. http://doi.org/10.1016/S2095-3119(16)615472

Indiyah, H., Ninuk, P., Pang, S. A., \& Hardjanto. (2017). Persepsi Petani terhadap Hutan Rakyat Pola Agroforestri di Kabupaten Wonogiri, Provinsi Jawa Tengah. Jurnal Penyuluhan, 13(1), 64-78.

Mamuko, F., Walangitan, H., \& Tilaar, W. (2016). Persepsi dan Partisipasi Masyarakat Dalam Upaya Rehabilitasi Hutan dan Lahan Di Kabupaten BoLaang Mongondow Timur.
Eugenia, 22(2), 80-92.

Masria, Golar, \& Ihsan, M. (2015). Persepsi dan Sikap Masyarakat Lokal Terhadap Hutan Di Desa Labuan Toposo Kecamatan Labuan Kabupaten Donggala. WARTA RIMBA, 3(2), 57-64.

Neil, A., Golar, \& Hamzari. (2016). Hutan Bukan Kayu Pada Taman Nasional Lore Lindu (Studi Kasus Desa Sidondo I Kecamatan Biromaru dan Desa Pakuli Kecamatan Gumbasa). EJurnal Mitra Sains, 4(1), 29-39.

Nishiguchi, S., \& Tabata, T. (2016). Assessment of social, economic, and environmental aspects of woody biomass energy utilization: Direct burning and wood pellets. Renewable and Sustainable Energy Reviews, 57, 1279-1286.

Sarwono, J. (2006). Metode Penelitian Kuantitatif dan kualitatif. Penerbit Graha Ilmu. Yogyakarta

Suryaningsih, W., Punaweni, H., \& Izzati, H. (2012). Persepsi dan Perilaku Masyarakat dalam Upaya Pelestarian Hutan Rakyat di Desa Karangrejo Kecamatan Loana Kabupaten Purworejo. Jurnal Ekosains, 4(3), 27-38.

Syaprillah, A. (2015). Aspek Hukum Pemberdayaam Masyarakat Di Sekitar Hutan Lindung Pulau Tarakan. Rechtsvinding, 4(2), 295-310.

Trevisan, A. C. D., Schmitt-filho, A. L., Farley, J., Fantini, A. C., \& Longo, C. (2016). Farmer perceptions, policy and reforestation in Santa Catarina , Brazil. Ecological Economics Journal, 130, 53-63.

Triyanto, H. (2009). Persepsi,Motivasi, sikap dan PerilakuMasyarakat Lokal Terhadap Keberadaan Hutan (kasus Di Kecamatan GN. Kencana, Kabupaten Lebak, Propinsi Banten). Institut Pertanian Bogor.

Winanti, M. R. (2010). Persepsi, Sikap dan Perilaku Masyarakat Terhadap Kelestarian Hutan. (Studi Kasus di desa Cinagara dan Desa Pasir Buncir Kecamatan Caringin, Kabupaten Bogor, Jawa Barat). Institut Pertanian Bogor. 